\title{
Developments in ONKOLOGIE
}

\author{
Hans-Joachim Schmoll \\ Zentrum für Innere Medizin, Klinikum der Medizinischen Fakultät, Martin-Luther-Universität, Halle/Saale, Germany
}

ONKOLOGIE was founded in 1978 as an educational journal for medical oncology, because several colleagues involved in the treatment of patients with cancer recognized in those days that the increasing mass of scientific developments in biology and in particular treatment of cancer needed to be presented to the practicing doctors in the field of oncology in a condensed form. Over the years, this educational approach has changed towards an interdisciplinary peer-reviewed journal for oncology publishing high-level original articles, informative reviews and educational case reports.

Today, ONKOLOGIE is the only peer-reviewed journal for the entire spectrum of oncologic research and treatment based in Germany. Many colleagues from different countries like Germany, Austria, Switzerland, Hungary, and the United States have influenced the development of OnKOLOGIE. Although the current Editorial Board and Associate Editors are mainly based in German-speaking countries, the proportion of Associate Editors from other European countries, the United States and Canada is increasing. This reflects the development of scientific communication via electronic media that has changed our way of gaining information and enables international discussion and cooperation.

The field of experimental and clinical research in oncology has always been advancing very fast. However, currently the number of important results of preclinical and clinical research is exploding and progress is made in extremely short time. This development, which provides great benefit for the patients with cancer, needs now even more than ever a scientific journal that focuses on the important developments and new treatments in oncology. More than before, oncology is an interdisciplinary field where the combined-modality treatment approach from the first step of diagnosis and through all treatment steps is essential. Therefore, ONKOLOGIE focusses not only on developments in medical oncology but, in particular, on all interdisciplinary aspects of diagnosis and treatment of malignant tumors.

The steadily increasing impact factor (1.154 in 2003) indicates the increasing importance of ONKOLOGIE and much credit must be given to the contributing authors and in particular the Associate Editors and members of the Editorial Board. These colleagues have devoted much of their time to the journal for peer review of original papers and to promote special articles and reviews.

Much of the positive development of our journal is based on decisions and actions which the Associate Editors have reached together with the previous Editor-in-Chief, Dr. Queißer. The current team of Editors will continue this important work. We are supported in this important task by the publishing house: thanks to the continuing investments of Karger publishers and the work of the editorial team ONKOLOGIE is always technically up to date. The journal has its own homepage, all articles are available online and manuscripts as well as the complete review process is now done online. This new feature will significantly speed up the review process and time to printing which is of high importance. Furthermore, instead of 6 editions/year ONKOLOGIE will now be published monthly, offering more space for peer-reviewed original articles and reviews. This will also considerably reduce the lead times.

In conclusion: ONKOLOGIE is set up for the next step of improvement. It is the contribution of original papers, high-quality editorials and reviews which composes the value of ONKOLOGIE for the oncologic scientific community. The editorial team at Karger as well as the Scientific Board will be dedicated to follow these goals.

Hans-Joachim Schmoll, Halle/Saale Editor-in-Chief

\begin{tabular}{ll}
\hline KARGER & ๑ 2005 S. Karger GmbH, Freiburg \\
Fax +497614520714 & Accessible online at: \\
$\begin{array}{l}\text { E-mail Information@Karger.de } \\
\text { www.karger.com }\end{array}$ & www.karger.com/onk
\end{tabular}

Prof. Dr. med. Hans-Joachim Schmoll

Zentrum für Innere Medizin, Klinikum der Medizinischen Fakultät Martin-Luther-Universität

Ernst-Grube-Str. 40, 06120 Halle/Saale, Germany

Tel. +49 345 557-2924, Fax -2950

E-mail hans-joachim.schmoll@medizin.uni-halle.de 